\title{
Taimikasvatuslämpötilan vaikutus kukkakaalisadon valmistumiseen
}

\author{
Risto TAhvonen
}

Kasvipatologian laitos, Helsingin yliopisto, 00710 Helsinki 71

\section{The effect of seedling temperature regime on the development of cauliflower yield}

Risto TaHVonen

Department of Plant Pathology, University of Helsinki, 00710 Helsinki 71, Finland

\begin{abstract}
Cauliflower seedlings raised at $20^{\circ} \mathrm{C}$ produced higher yield than those raised at $14^{\circ} \mathrm{C}$. The shortest harvesting period was obtained for $3-4$ week old seedlings raised at $20^{\circ} \mathrm{C}$. A $1-2$ week cold treatment $\left(8^{\circ} \mathrm{C}\right)$ on $4-5$ week old seedlings raised at $20^{\circ} \mathrm{C}$ shortened the harvesting period and reduced the number of undeveloped curds.
\end{abstract}

\section{Johdanto}

Kukkakaalin viljelyssä on Suomessa ollut vaikeutena sadon epätasainen valmistuminen. Lämpiminä kasvukausina kuten vuosina 1972 ja 1973 ei kukkakaali valmistunut monin paikoin lainkaan. Pitkä sadonkorjuuaika, usein jopa yli kuukauden, nostaa voimakkaasti viljelykustannuksia useiden poimintakertojen vuoksi.

Kukkakaalilla on kaksi selvästi havaittavaa kehitysvaihetta, vegetatiivinen ja generatiivinen vaihe. Vegetatiivisessa vaiheessa kukkakaali kasvattaa vain lehtiä. Kasvin nuoruusvaiheessa, joka kestää hyvissä olosuhteissa 3-5 viikkoa, ei ulkoisilla olosuhteilla voida vaikuttaa vegetatiivisen vaiheen päättymiseen (WIEBE 1972 a).

Vegetatiivinen kasvuvaihe jatkuu nuoruusvaiheen jälkeen, jos lämpötila on yli $20^{\circ} \mathrm{C}$ (SKAPSKI ja OYER 1964). Kukkaan virittyminen tapahtuu lämpötila-alueella $2-17^{\circ} \mathrm{C}$, nopeimmin $7-12^{\circ} \mathrm{C}$ :ssa (WIEBE $1972 \mathrm{~b}$ ).

Kukkakaalin taimien kasvu nopeutuu ja samalla nuoruusvaihe lyhenee taimikasvatuslämpötilan noustessa $22^{\circ}$ C:een (WIEBE 1972 c). Suomessa on kuitenkin perinteinen kaalien taimikasvatuslämpötila ollut $12-17^{\circ} \mathrm{C}$.

Tämän tutkimuksen tarkoituksena oli selvittää mahdollisuuksia vaikuttaa satokauden lyhenemiseen ja sadon ajoittumiseen kukkakaalin kukinnan kannalta tarkoituksenmukaisella taimikasvatuslämpötilaohjelmalla. Kokeet on 
suoritettu 1973 Helsingin yliopiston puutarhatieteen laitoksella ja 1975-76 Helsingin yliopiston kasvipatologian laitoksella. Vuonna 1975 tehdyn progradu-työn (REINIKAINEN 1975) antamia tuloksia on käytetty viimeisien kokeiden suunnittelussa.

\section{Aineisto ja menetelmät}

Vuoden 1973 kokeissa oli kaksi taimikasvatuslämpötilaa, $14^{\circ} \mathrm{C}$ ja $20^{\circ} \mathrm{C}$. Taimikasvatusajat olivat 3, 4, 5 ja 6 viikkoa. Lajike oli Erfurter 291.

Vuonna 1975 kasvatettiin Erfurter 291- ja Igloo-lajiketta 20 C:ssa 24-38 vuorokautta, minkä jälkeen taimet siirrettiin $8^{\circ}$ C:een 7,10 ja 14 vuorokaudeksi siten, että yhteenlaskettu taimikasvatusaika oli 38 ja 45 vuorokautta. Käsittelemättöminä koejäseninä olivat 31,38 ja 45 vuorokautta $20^{\circ} \mathrm{C}$ :ssa kasvaneet taimet (taulukko 2). Koetta häiritsi valmiiksi lannoitetun turpeen epätasainen ravinnepitoisuus. Vuonna 1976 kasvatettiin Igloo-lajiketta $20^{\circ} \mathrm{C}$ :ssa $21-35$ vrk. Kylmäkäsittelyt tehtiin $8^{\circ} \mathrm{C}$ :ssa 7,10 ja 14 vrk siten, että yhteenlaskettu taimikasvatusaika oli 35 ja 42 vrk. Taimet saivat n. 2000 lux. tekovaloa $24 \mathrm{~h} /$ vrk matalapaine-elohopealoistelampuilla kylmäkäsittelyjen ajan. Käsittelemättöminä koejäseninä olivat 21 ja 28 vrk $20^{\circ} \mathrm{C}$ :ssa kasvaneet taimet (taulukko 3). Taimikasvatuksen lopussa tutkittiin kasvupisteiden halkaisijat, mikä selvittää kasvien siirtymistä vegetatiivisesta generatiiviseen vaiheeseen (WIEBE 1972 c). Kaikki kasvatukset ajoitettiin siten, että istutuspäivä (kesäkuun 1-2 viikko) oli sama jokaisella koejäsenellä.

\section{Tulokset ja tulosten tarkastelu}

Kukkakaali antoi merkitsevästi paremman sadon lämpöisessä kasvatetuista kuin kylmässä kasvatetuista taimista. Kuuden viikon taimikasvatusaika alensi merkitsevästi satoa (taulukko 1). Lämpimässä kasvatetuilla 3 ja 4 viikon ikäisillä taimilla oli muita lyhyempi sadonkorjuuaika.

Taulukko 1. Taimikasvatuslämpötilan ja -ajan vaikutus kukkakaalin 'Erfurter 291' satoon v. 1973.

Table 1. Effect of the raising temperature and time on the yield of 'Evfurter 291' cauliflower in 1973.

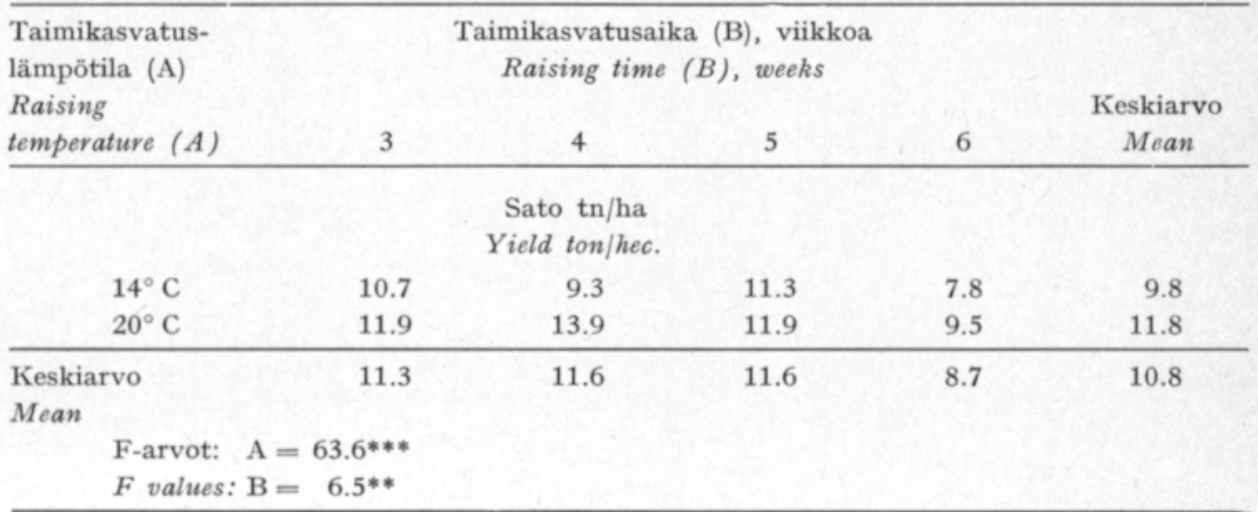


Taulukko 2. Taimikasvatus- ja kylmäkäsittelyajan vaikutus kukkakaalin satoon v. 1975 . Table 2. Effect of seedling temperature combinations on the yield of cauliflower in 1975.

\begin{tabular}{|c|c|c|c|c|c|}
\hline \multirow{2}{*}{$\begin{array}{l}\text { Koejäsen } \\
\text { Treatment } \\
\quad \text { No. }\end{array}$} & \multicolumn{3}{|c|}{$\begin{array}{l}\text { Kasvatusaika (vrk) } \\
\text { Raising time (days) }\end{array}$} & \multicolumn{2}{|c|}{$\begin{array}{l}\text { Sato } \mathrm{kg} / \mathrm{kasvi} \\
\text { Yield } \mathrm{kg} / \text { plant }\end{array}$} \\
\hline & $20^{\circ} \mathrm{C}$ & ja & $8^{\circ} \mathrm{C}$ & 'Igloo' & 'Erfurter 291' \\
\hline I & 31 & & 14 & 0.33 & 0.50 \\
\hline II & 35 & & 10 & 0.41 & 0.44 \\
\hline III & 38 & & 7 & 0.38 & 0.33 \\
\hline IV & 24 & & 14 & 0.39 & 0.33 \\
\hline V & 28 & & 10 & 0.42 & 0.37 \\
\hline VI & 31 & & 7 & 0.41 & 0.42 \\
\hline VII & 45 & & 0 & 0.51 & 0.34 \\
\hline VIII & 38 & & 0 & 0.38 & 0.37 \\
\hline \multirow[t]{2}{*}{ IX } & 31 & & 0 & 0.41 & 0.38 \\
\hline & \multicolumn{3}{|r|}{$\mathrm{LSD}_{\mathrm{t}_{0.05}}$} & $=0.12$ & 0.09 \\
\hline
\end{tabular}

Taulukko 3. Taimikasvatus- ja kylmäkäsittelyajan vaikutus Igloo-kukkakaalilajikkeen satoon ja taimien kasvupisteiden halkaisijoihin ennen istutusta v. 1976.

Table 3. Effect of seedling temperature combinations on the yield and diameter of growingpoint of 'Igloo' cauliflower seedlings before planting in 1976.

\begin{tabular}{|c|c|c|c|c|c|}
\hline \multirow{2}{*}{$\begin{array}{c} \\
\text { Koejäsen } \\
\text { Treatment } \\
\text { No. }\end{array}$} & \multicolumn{3}{|c|}{$\begin{array}{l}\text { Kasvatusaika (vrk) } \\
\text { Growing time (days) }\end{array}$} & \multirow{2}{*}{$\begin{array}{l}\text { Sato kg/ kasvi } \\
\text { Yield kg/plant }\end{array}$} & \multirow{2}{*}{$\begin{array}{l}\text { Kasvupisteen } \\
\text { halkaisija, mm } \\
\text { Diameter of } \\
\text { growing point, mm }\end{array}$} \\
\hline & $20^{\circ} \mathrm{C}$ & $\begin{array}{l}\mathrm{ja} \\
\text { and }\end{array}$ & $8^{\circ} \mathrm{C}$ & & \\
\hline I & 28 & & 14 & 0.64 & 0.59 \\
\hline II & 32 & & 10 & 0.75 & 0.64 \\
\hline III & 35 & & 7 & 0.86 & 0.47 \\
\hline IV & 21 & & 14 & 0.58 & 0.18 \\
\hline V & 25 & & 10 & 0.62 & 0.23 \\
\hline VI & 28 & & 7 & 0.72 & 0.22 \\
\hline VII & 21 & & 0 & 0.58 & 0.18 \\
\hline \multirow[t]{2}{*}{ VIII } & 28 & & 0 & 0.73 & 0.26 \\
\hline & & & $\mathrm{D}_{\mathrm{t}_{0.05}}$ & 0.15 & \\
\hline
\end{tabular}

Lämpöisessä tehdyn taimikasvatuksen pãätteeksi annetut kylmäkäsittelyt eivät alentaneet satoja (taulukko 2 ja 3 ). Kukkakaalintaimet, jotka saivat $4-5$ viikon taimikasvatuksen lisäksi $2-1$ viikon kylmäkäsittelyn, siirtyivät tai olivat siirtymässä generatiiviseen vaiheeseen jo taimikasvatuksen aikana kasvupistemittausten mukaan (taulukko 3). Alle 4 viikon ikäisille taimille annetut kylmäkäsittelyt eivät vaikuttaneet kasvupisteiden halkaisijaan.

Yli neljän viikon ikäisille taimille annetut kylmäkäsittelyt aiheuttivat voimakkaan satohuipun sadonkorjuuajan alkuosalle molemmilla lajikkeilla. Käsittelemättömillä ja alle neljän viikon ikäisillä kylmäkäsitellyillä taimilla sato valmistui tasaisesti koko sadonkorjuuajan ja oli keskimäärin $2-3$ viikkoa myöhempi kuin muilla (kuva 1, 2 ja 3). Vuonna 1976 käsittelemättömillä 
Kuva 1. Kukkakaalintaimien 'Erfurter 291' kylmäkäsittelyjen vaikutus sadon valmistumiseen. Fig. 1. Effect of seedling cold treatments on development of the yield of 'Erfurter 291' cauliflower.

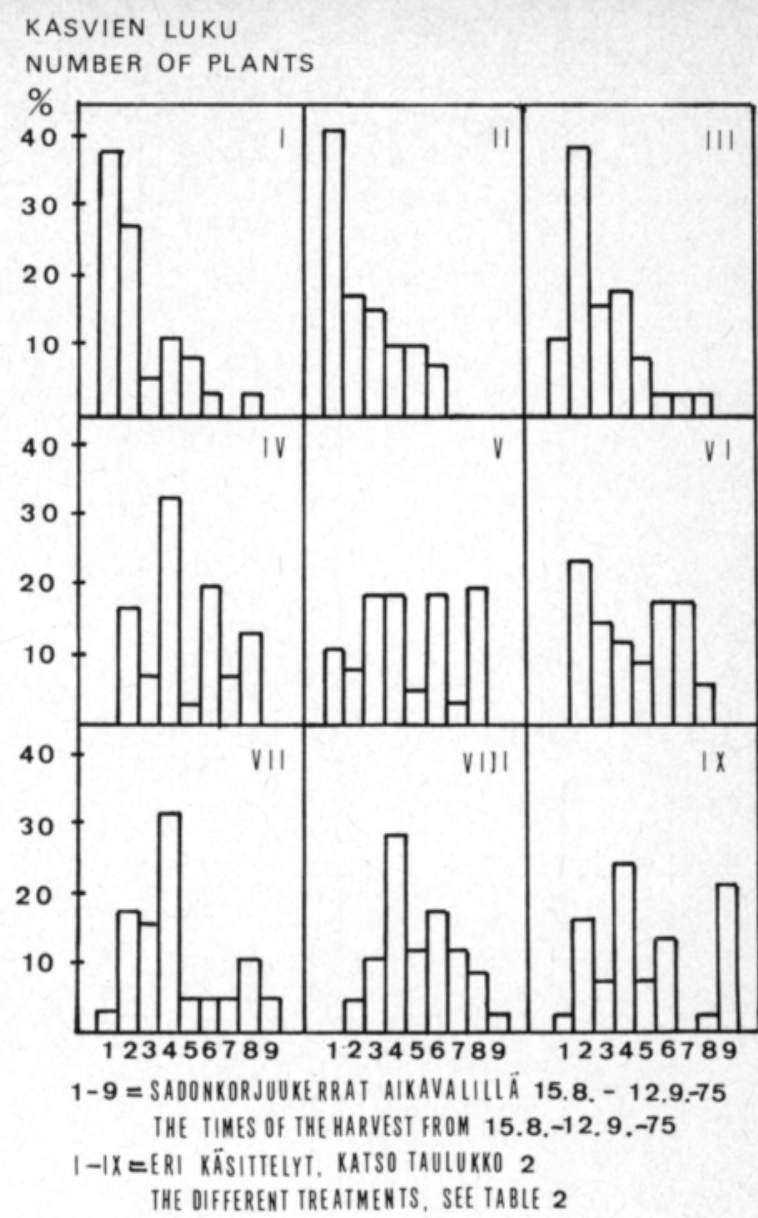

ja alle 4 viikon ikäisillä käsitellyillä taimilla oli merkitsevästi enemmän valmistumattomia kukintoja kuin kylmäkäsitellyillä yli 4 viikon ikäisillä taimilla (kuva 3).

Suoritettujen kokeiden mukaan voidaan hyvissä olosuhteissa kasvattaa virittymiselle altis kukkakaalintaimi $30-35$ vuorokaudessa myös myöhäisillä lajikkeilla. Perinteisesti käytetyssä kaalien alle $17^{\circ} \mathrm{C}: n$ taimikasvatuslämpötilassa kukkakaali alkaa siirtyä kukintavaiheeseen välittömästi nuoruusvaiheen ohitettuaan, mistä on seurauksena taimien eriaikainen virittyminen ja siitä aiheutuva useita viikkoja kestävä sadonkorjuuaika. Yli $18^{\circ} \mathrm{C}$ :n lämpötilassa taimet ohittavat nopeimmin nuoruusvaiheen ja pakotetaan pysymään tämän jälkeen vegetatiivisessa vaiheessa. Kun taimille tehdään 7-10 vrk:n kylmäkäsittely, joka käytännössä tarkoittaa voimakasta tuuletusta päivä- ja yölämpötilan alentamiseksi eli kyseessä on ns. taimien perinteinen 'karaisuvaihe' ennen istutusta, kaikki taimet alkavat siirtyä kukintavaiheeseen samanaikaisesti, jolloin myös sato valmistuu normaalia lyhyempänä aikana ja on määrällisesti ja laadullisesti vähintään yhtä hyvä kuin muilla taimilla. Hetkellinen korkea lämpötila ei aiheuta häiriötä virittymiseen, kun vuorokautinen keskilämpötila pysyy riittävän alhaisena (WIEBE 1974). 


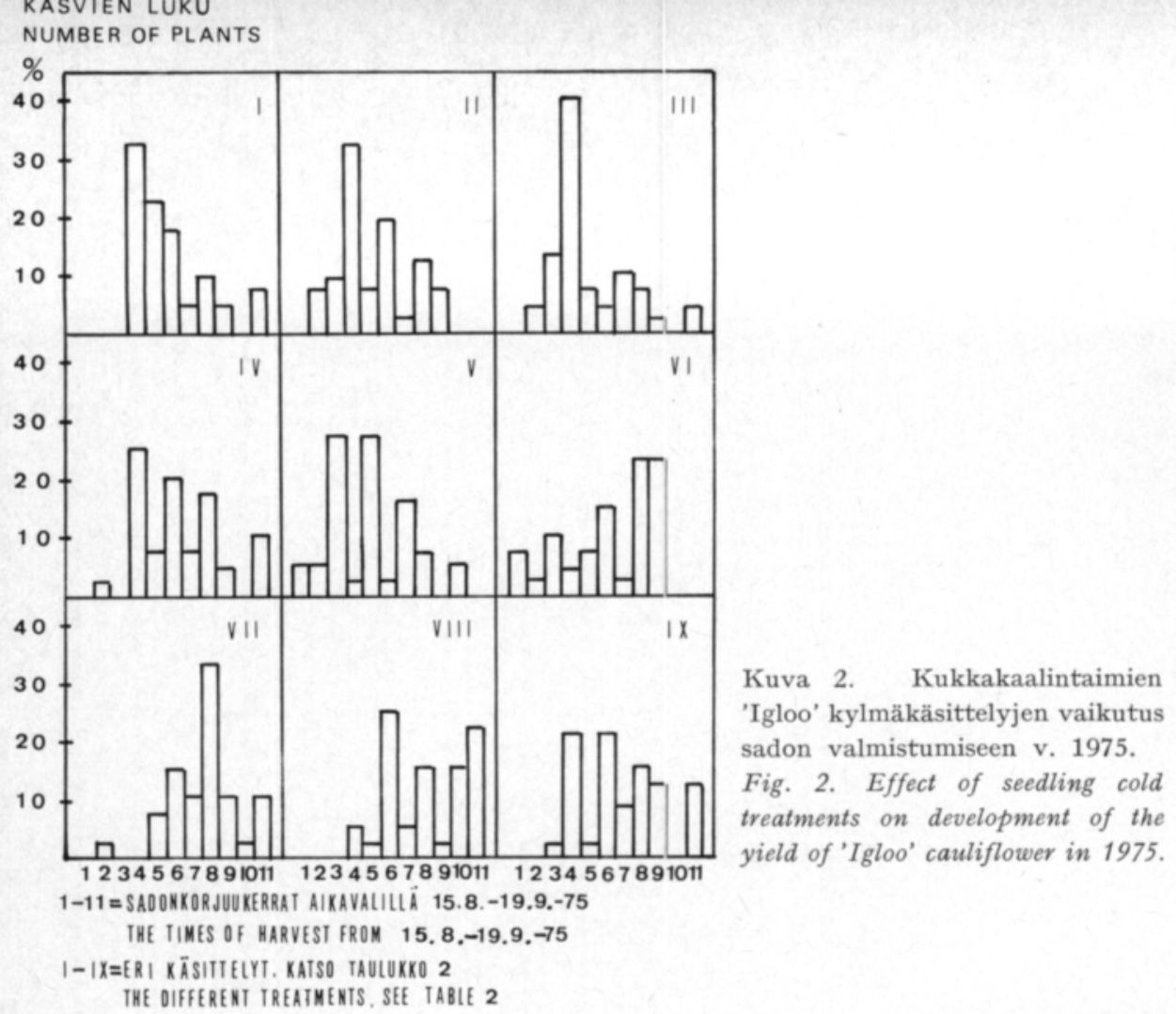

KASVIEN LUKU

NUMBER OF PLANTS

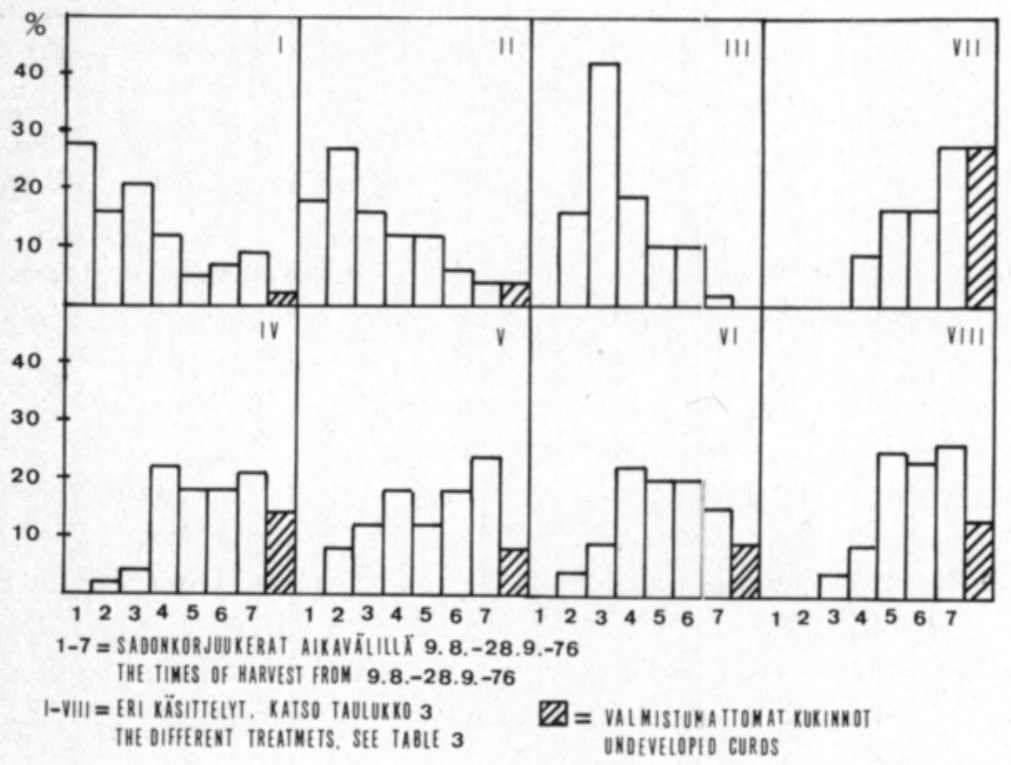

Kuva 3. Kukkakaalintaimien 'Igloo' kylmäkäsittelyjen vaikutus sadon valmistumiseen v. 1976.

Fig. 3. Effect of seedling cold treatments on development of the yield of 'Igloo' cauliflower in 1976. 
Virityksen onnistumisesta sellaisina hellekesinä, jolloin normaalisti kasvatetuista taimista ei saada lainkaan satoa, ei tämän tutkimuksen yhteydessä saatu riittävästi kokemuksia, koska kasvukaudet eivät olleet normaalia lämpimämpiä.

\section{Tiivistelmä}

Satokauden lyhentämiseksi ja sadon varmistamiseksi selvitettiin kahdessa eri lämpötilassa eri aikoja kasvatettujen kukkakaalintaimien sekä lämpöisessä tehdyn taimikasvatuksen päätteeksi annettujen erimittaisten kylmäkäsittelyjen vaikutusta sadon ajoittumiseen ja määrään. Kokeet tehtiin vuosina 1973, 1975 ja 1976 Viikissä.

Lämpöisessä, $20^{\circ} \mathrm{C}$, kasvatettujen kukkakaalintaimien 'Erfurter 291' sato oli suurempi kuin kylmässä, $14^{\circ} \mathrm{C}$, kasvatettujen taimien. Lämpöisessä kasvatetuilla 3 ja 4 viikon ikäisillä taimilla oli lyhin sadonkorjuuaika.

Lämpöisessä kasvatetuilla $4-\mathbf{5}$ viikon ikäisille kukkakaalin taimille ('Erfurter 291' ja 'Igloo') annettu kylmäkäsittely $8^{\circ} \mathrm{C}$ :ssa aikaistutti satoa ja lyhensi sadonkorjuuaikaa sekä vähensi Igloo-lajikkeella valmistumattomien kukintojen määrää.

\section{KIRJALLISUUSLUETTELO}

REINIKAINEN, O. 1975. Kukkakaalin taimien kylmäkäsittelyn vaikutus sadon ajoittumiseen. Pro-gradu-työ. Helsinki.

SKAPSKI, H. \& OYER, E. B. 1964. The influence of pretranspanting variables on the growth and development of cauliflower plants. Proc. Amer. Soc. Hort. Sci. 85: 354-385.

Wiebe, H. J. 1972 a. Wirkung von Temperatur und Licht auf Wachstum und Entwicklung von Blumenkohl. I. Dauer der Jugendphase für die Vernalisation. Gartenb.wiss. 37: $165-178$.

- 1972 b. Wirkung von Temperatur und Licht auf Wachstum und Entwicklung von Blumenkohl. II. Optimale Vernalisationstemperatur und Vernalisationsdauer. Gartenb.wiss. 37: 293-303.

- 1972 c. Wirkung von Temperatur und Licht auf Wachstum und Entwicklung von Blumenkohl. III. Vegetative Phase. Gartenb.wiss. 37:455-469.

- 1974. Zur Bedeutung des Temperaturverlaufs und der Lichtintensität auf den Vernalisationseffekt bei Blumenkohl. Gartenb.wiss. 39:1-7.

Käsikirjoitus saapunut 2.7.1979. 